\title{
Surface and thermomechanical characterization of polyurethane networks based on poly(dimethylsiloxane) and hyperbranched polyester
}

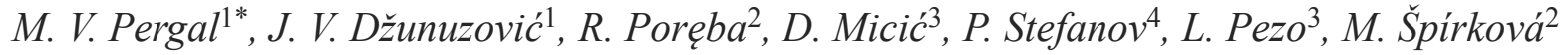 \\ ${ }^{1}$ Institute of Chemistry, Technology and Metallurgy (ICTM)-Center of Chemistry, University of Belgrade, Studentski trg \\ 12-16, 11000 Belgrade, Serbia \\ ${ }^{2}$ Institute of Macromolecular Chemistry AS CR, v.v.i. (IMC), Nanostructured Polymers and Composites Department, \\ Heyrovskeho nam. 2, 16206 Prague, Czech Republic \\ ${ }^{3}$ Institute of General and Physical Chemistry, University of Belgrade, Studentski trg 12-16, 11000 Belgrade, Serbia \\ ${ }^{4}$ Institute of General and Inorganic Chemistry, Bulgarian Academy of Sciences, Acad. Georgi Bonchev 11, 1113 Sofia, \\ Bulgaria
}

Received 3 April 2013; accepted in revised form 10 June 2013

\begin{abstract}
Two series of polyurethane (PU) networks based on Boltorn ${ }^{\circledR}$ hyperbranched polyester (HBP) and hydroxyethoxy propyl terminated poly(dimethylsiloxane) (EO-PDMS) or hydroxy propyl terminated poly(dimethylsiloxane) (HPPDMS), were synthesized. The effect of the type of soft PDMS segment on the properties of PUs was investigated by Fourier transform infrared spectroscopy (FTIR), contact angle measurements, surface free energy determination, X-ray photoelectron spectroscopy (XPS), scanning electron microscopy (SEM), atomic force microscopy (AFM), dynamic mechanical thermal analysis (DMTA) and differential scanning calorimetry (DSC). The surface characterization of PUs showed existence of slightly amphiphilic character and it revealed that PUs based on HP-PDMS have lower surface free energy, more hydrophobic surface and better waterproof performances than PUs based on EO-PDMS. PUs based on HPPDMS had higher crosslinking density than PUs based on EO-PDMS. DSC and DMTA results revealed that these newlysynthesized PUs exhibit the glass transition temperatures of the soft and hard segments. DMTA, SEM and AFM results confirmed existence of microphase separated morphology. The results obtained in this work indicate that PU networks based on HBP and PDMS have improved surface and thermomechanical properties.
\end{abstract}

Keywords: coatings, poly(urethane-siloxane)s, hyperbranched polyester, surface free energy, dynamic mechanical analysis

\section{Introduction}

Polyurethane (PU) coatings are very important because of their excellent mechanical properties, good hardness and high abrasion resistance $[1,2]$. The properties of PU coatings can be tailor-made by appropriate selection of the constituents such as soft and hard segments and using an appropriate amount of crosslinker. However, poor thermal stability of conventional PU coatings limits their high temperature applications $[3,4]$. For PU to be useful at high temperatures, its architecture should be modified by introducing poly(dimethylsiloxane) (PDMS) segments in the PU backbone [5]. Therefore, many investigations have been carried out in which PDMS was used as a component of polyurethane to improve PU properties, such as water resistance, flame resistance, and thermal stability [6, 7]. Furthermore, PU with PDMS has been tested as a component of foulrelease type coatings due to its smooth and nonstick surface [6].

\footnotetext{
*Corresponding author, e-mail: marijav@chem.bg.ac.rs (C) BME-PT
} 
PDMS, a major compound in the class of polysiloxanes, has a number of unique and specific properties such as high thermal and oxidative stability, good water resistance, biocompatibility, low surface tension, low glass transition temperature, high permeability to many gases and very good UV stability $[8,9]$. However, poor mechanical properties and abrasion resistance of PDMS limit its application in many fields [10]. Another shortcoming is its incompatibility with organic polymers arising from the non-polar nature of the PDMS based on its very low solubility parameter $\left(14.9 \mathrm{~J}^{1 / 2} \cdot \mathrm{cm}^{-3 / 2}\right)$ compared to other polymers $\left(17.6-28.6 \mathrm{~J}^{1 / 2} \cdot \mathrm{cm}^{-3 / 2}\right)$. The nonpolar nature of the PDMS structure combined with the weak intermolecular interaction leads to the creation of a polymer phase that is both thermodynamically and mechanically incompatible, not only with the PU components, but also with all organic monomers and with other polymer. This leads to the formation of phase-segregated morphology of PUs [8]. Polyurethane networks based on PDMS macrodiols and hyperbranched polyesters (HBP) as crosslinkers introduced into the hard segment domains can combine properties of all components, making these networks good candidates for coating applications. The large number of terminal hydroxyl groups present in Boltorn ${ }^{\circledR}$ HBPs enables fast formation of networks that have good mechanical properties, as well as good resistance to chemicals [11-14], while the presence of PDMS contributes to the good thermal and surface properties, and to elasticity of the highly crosslinked materials. In our previous studies, we have investigated the influence of the content of $\alpha, \omega$-dihydroxyethoxy propyl-poly(dimethylsiloxane) (EO-PDMS) and type of HBPs on the swelling behavior, morphological, thermal and thermomechanical properties of PU networks [15-21]. These results confirmed that physical and thermal properties are related to the crosslinking density, hydrogen bonding interactions, microphase separation and content of EO-PDMS soft segment. The aim of our previous studies was to prepare poly (urethane-siloxane) networks with good thermal, mechanical and surface properties, which would be suitable for coating applications.

As far as we are aware, there is a paucity of peerreviewed literature on the surface free energy of these particular polyurethanes prepared in the form of films, which is especially important for coatings.
In the present work, therefore, we have studied the surface and thermomechanical properties of PU networks prepared with different types of soft PDMS segment, as part of our efforts to produce improved PUs. Two series of PU networks based on hydroxyethoxy propyl terminated PDMS or hydroxy propyl terminated PDMS as the soft segment and 4,4'methylenediphenyl diisocyanate and Boltorn ${ }^{\circledR}$ hyperbranched polyester of the third pseudo generation (BH-30) as components of hard segment were prepared. The PU networks were characterized by Fourier transform infrared spectroscopy (FTIR), contact angle measurements, surface free energy determination, X-ray photoelectron spectroscopy (XPS), scanning electron microscopy (SEM), atomic force microscopy (AFM), dynamic mechanical thermal analysis (DMTA) and differential scanning calorimetry (DSC).

\section{Experimental}

\subsection{Materials}

$\alpha, \omega$-Dihydroxyethoxy propyl-poly(dimethylsiloxane) (EO-PDMS) and $\alpha, \omega$-dihydroxypropyl-poly (dimethylsiloxane) (HP-PDMS) supplied from ABCR (Karlsruhe, Germany) were dried over molecular sieves $(0.4 \mathrm{~nm})$ before use. The average molecular weights, $M_{\mathrm{n}}$, of the EO-PDMS and HP-PDMS were calculated from ${ }^{1} \mathrm{H}$ NMR spectroscopy. In addition, the degree of polymerization of the PDMSblock in the EO-PDMS and HP-PDMS prepolymers was determined as the relative intensities of the $\mathrm{Si}-\mathrm{CH}_{3}$ protons signals and the terminal $-\mathrm{CH}_{2}-$ protons in the ethylene oxide residue or the $-\mathrm{CH}_{2}-$ protons arising from the PDMS propylene groups which were connected to oxygen atoms in hydroxyl groups, respectively. Therefore, the degree of polymerization of PDMS-block in the EO-PDMS and HP-PDMS prepolymers was 12.8 and 10.6 . The $M_{\mathrm{n}}$ of the prepolymer EO-PDMS was $1200 \mathrm{~g} / \mathrm{mol}$ [22], while for the prepolymer HP-PDMS it was $960 \mathrm{~g} / \mathrm{mol} .4,4^{\prime}-$ Methylenediphenyl diisocyanate (MDI) (supplied from Aldrich, Steinheim, Germany), with an isocyanate content of $33.6 \mathrm{wt} \%$, was used as received. Commercially available Boltorn ${ }^{\circledR}$ hydroxy-functional aliphatic HBP of the third pseudo generation (BH-30) was kindly supplied by Perstorp Specialty Chemicals $\mathrm{AB}$ (Sweden) and dried at $50^{\circ} \mathrm{C}$ under vacuum for $48 \mathrm{~h}$ prior to use. The aliphatic hyperbranched polyester is based on 2,2-bis(hydrox- 
ymethyl)propionic acid as a monomer and tetrafunctional ethoxylated pentaerythrytol as a core [23]. For the exact calculation of the amounts of all components necessary for the synthesis of PUs, the value of the molecular weight determined by vapor pressure osmometry $\left(M_{\mathrm{n}}=3080 \mathrm{~g} / \mathrm{mol}\right)$ and hydroxyl number of BH-30 determined by titration method $(H N=474.1 \mathrm{mg} \mathrm{KOH} / \mathrm{g}$ ) were used. Consequently, the exact functionality, $f_{\mathrm{n}}$, of the BH-30 used was calculated $\left(f_{\mathrm{n}}=26\right)$ [24]. The catalyst was stannousoctanoate $\left(\mathrm{Sn}(\mathrm{Oct})_{2}\right)$, supplied from Aldrich (St. Louis, USA). The solvent $N$-methyl-2-pyrrolidone (NMP) supplied from Acros (Geel, Belgium) was dried over calcium-hydride and distilled before use. Tetrahydrofuran (THF) supplied from J.T. Baker (Center Valley, USA) was refluxed with lithiumaluminum hydride and distilled before use. Formamide (analytically pure, Merck, Darmstadt, Germany) and diiodomethane (analytically pure, UCB, Brussels, Belgium) were used as received.

\subsection{Synthesis of PU films based on PDMS and control sample}

Two series of PU networks based on PDMS macrodiols, MDI and Boltorn ${ }^{\circledR}$ HBP were synthesized by a two-step polymerization in solution, using a mixture of $N$-methyl-2-pyrrolidone/tetrahydrofuran as the solvent and stannous octanoate as the catalyst. Macrodiols used for the preparation of samples of series PUS1 (PUS1-15 and PUS1-30) and PUS2 (PUS2-15 and PUS2-30) were hydroxyethoxy propyl terminated PDMS and hydroxy propyl terminated PDMS, respectively. Each series of the synthesized PUs consisted of two samples of different PDMS content (15 and $30 \mathrm{wt} \%$ ), which, in this study, is marked by the last two numbers in the name of prepared samples. The total molar ratio of $-\mathrm{NCO}$ (from $\mathrm{MDI}$ ) and - $\mathrm{OH}$ groups (from PDMS macrodiol and BH-30) was, for all samples, kept constant (NCO/ $\mathrm{OH}=1.05$ ) $[25-27]$. Catalyst concentration was kept at $0.02 \mathrm{wt} \%$ [25-27]. The details for the synthesis of similar PU networks are given in our previously published papers [16-21]. Compositions of the synthesized PUs and weights of the reactants used for the synthesis of PUs are presented in Table 1. PU samples were synthesized in $100 \mathrm{~mL}$ four-neck round-bottom flasks, placed in a silicone oil bath and connected to an inlet for dry argon, a mechanical stirrer, a dropping funnel and a reflux condenser. Calculated amounts of macrodiol and MDI were
Table 1. Compositions of the synthesized PUs and weights of reactants used for their preparation

\begin{tabular}{|l|c|c|c|c|}
\hline Sample & $\begin{array}{c}\text { Soft segment } \\
\text { content } \\
{[\mathbf{w t} \% \mathbf{l}]}\end{array}$ & $\begin{array}{c}\text { PDMS } \\
\text { macrodiol } \\
\text { [g] }\end{array}$ & $\begin{array}{c}\text { MDI } \\
{[\mathbf{g}]}\end{array}$ & $\begin{array}{c}\text { BH-30 } \\
{[\mathbf{g}]}\end{array}$ \\
\hline PUS1-15 & 15 & 2.5004 & 7.7706 & 6.4615 \\
\hline PUS1-30 & 30 & 4.0004 & 5.3212 & 4.0128 \\
\hline PUS2-15 & 15 & 2.5004 & 7.7714 & 6.3965 \\
\hline PUS2-30 & 30 & 4.0004 & 5.4258 & 3.9096 \\
\hline MDI-BH30 & 0 & 0 & 5.0002 & 4.5128 \\
\hline
\end{tabular}

weighed into reaction flask at room temperature, dissolved in the mixture of NMP/THF and then heated up to $40^{\circ} \mathrm{C}$ under an argon atmosphere. The reaction started by the introduction of a solution of $\mathrm{Sn}(\mathrm{Oct})_{2}$ in NMP. The reaction mixture was stirred for $30 \mathrm{~min}$ (for the PUS1 series) or $20 \mathrm{~min}$ (for the PUS2 series) at $40^{\circ} \mathrm{C}$ to prepare the NCO-terminated prepolymer, i.e. until the theoretical $\mathrm{NCO}$ content was attained. The NCO content was controlled by the dibutylamine back-titration method [28]. In the second stage of the reaction, a dilute solution of BH-30 in NMP was added drop-wise to the NCOterminated prepolymer and the reaction was continued at $40^{\circ} \mathrm{C}$ for $10 \mathrm{~min}$. Finally, the obtained reaction mixture was cast into Petri dishes. The crosslinking reaction was continued in a force-draft oven during $40 \mathrm{~h}$ at $80^{\circ} \mathrm{C}$ and $1 \mathrm{~h}$ at $110^{\circ} \mathrm{C}$, and finally $10 \mathrm{~h}$ at $50^{\circ} \mathrm{C}$ in a vacuum oven. The thickness of the synthesized yellow PU films was about $1 \mathrm{~mm}$.

The synthesis of the control (MDI-BH30) sample, prepared without PDMS macrodiol, was carried out at the same conditions, but the crosslinking reaction proceeded at ambient temperature for $24 \mathrm{~h}$, and then in a vacuum oven at $50^{\circ} \mathrm{C}$ for $10 \mathrm{~h}$ and at $80^{\circ} \mathrm{C}$ for $12 \mathrm{~h}$.

\subsection{Characterization}

FTIR spectra of PUs were recorded using the attenuated total reflection (ATR) mode on Nicolet 6700 FTIR spectrometer (Madison, USA). The scanning range was from 500 to $4000 \mathrm{~cm}^{-1}$ at the resolution of $4 \mathrm{~cm}^{-1}$, and 64 scans were collected for each sample.

The static contact angles were measured using a contact angle analyzer (Krüss DSA100, Hamburg, Germany), equipped with software for a drop shape analysis. The static contact angle $(\theta)$ was measured by a sessile drop method at a temperature of $23^{\circ} \mathrm{C}$. Single drops of test liquids with volumes of $20 \mu \mathrm{L}$ were deposited on the polymer film surface and the 
contact angles were measured after $30 \mathrm{~s}$. In all cases, at least five measurements were used, and the average contact angle was calculated. The equilibrium contact angle is defined as the angle between the solid surface and a tangent, drawn on the drop-surface, passing through the triple-point atmosphere-liquidsolid [29]. The relationship between three interfacial tensions is given by Young's Equation (1):

$$
\cos \theta=\frac{\gamma_{\text {solid/vapor }}-\gamma_{\text {solid/liquid }}}{\gamma_{\text {liquid/vapor }}}
$$

where $\gamma_{\text {solid/vapor }}$ is the energy of the surface, $\gamma_{\text {solid/liquid }}$ is the interfacial tension between the solid and the drop of liquid, $\gamma_{\text {liquid/vapor }}$ is the liquid-vapor surface tension and ? is the contact angle of $\theta$ the drop with the surface.

The surface free energy of PUs was calculated according to the van Oss Chaudhury Good method [30]. This method has been widely used to investigate the surface free energy of polymer films that are used as coatings. For reliable determination of the surface energy, three test liquids (distilled water, formamide and diiodomethane) with known surface tensions $[31,32]$, ranging from very polar to nonpolar, were utilized to determine the surface free energy of the PU films, as shown in Table 2. The surface free energy and its components were calculated by solving the following set Equations (2) [30]:

$\gamma_{\mathrm{LV} 1}\left(1-\cos \theta_{1}\right)=2 \sqrt{\gamma_{\mathrm{S}}^{\mathrm{LW}} \gamma_{\mathrm{LV} 1}^{\mathrm{LW}}}+\sqrt{\gamma_{\mathrm{S}}^{+} \gamma_{\mathrm{LV} 1}^{-}}+\sqrt{\gamma_{\mathrm{S}}^{-} \gamma_{\mathrm{LV} 1}^{+}}$

$\gamma_{\mathrm{LV} 2}\left(1-\cos \theta_{2}\right)=2 \sqrt{\gamma_{\mathrm{S}}^{\mathrm{LW}} \gamma_{\mathrm{LV} 2}^{\mathrm{LW}}}+\sqrt{\gamma_{\mathrm{S}}^{+} \gamma_{\mathrm{LV} 2}^{-}}+\sqrt{\gamma_{\mathrm{S}}^{-} \gamma_{\mathrm{LV} 2}^{+}}$

$\gamma_{\mathrm{LV} 3}\left(1-\cos \theta_{3}\right)=2 \sqrt{\gamma_{\mathrm{S}}^{\mathrm{LW}} \gamma_{\mathrm{LV} 3}^{\mathrm{LW}}}+\sqrt{\gamma_{\mathrm{S}}^{+} \gamma_{\mathrm{LV} 3}^{-}}+\sqrt{\gamma_{\mathrm{S}}^{-} \gamma_{\mathrm{LV} 3}^{+}}$

$\gamma_{\mathrm{S}}=\gamma_{\mathrm{S}}^{\mathrm{LW}}+\gamma_{\mathrm{S}}^{\mathrm{AB}}=\gamma_{\mathrm{S}}^{\mathrm{LW}}+2 \sqrt{\gamma_{\mathrm{S}}^{+} \gamma_{\mathrm{S}}^{-}}$

where $\gamma_{\mathrm{s}}$ is the surface free energy that can be divided into two components: the dispersive $\left(\gamma^{\mathrm{LW}}\right)$ which represent the van der Waals interactions, and the polar component $\left(\gamma^{\mathrm{AB}}\right)$ including the Lewis acid parameter $\left(\gamma^{+}\right)$and the Lewis base parameter $\left(\gamma^{-}\right) \cdot \gamma_{\mathrm{LV}}$ is the surface tension of the liquid in equilibrium with its own vapor. The total surface energy and its components could be obtained by solving Equation (2), since values of $\gamma_{\mathrm{LV}}^{\mathrm{LW}}, \gamma_{\mathrm{LV}}^{+}, \gamma_{\mathrm{LV}}^{-}$are known.

The surface composition of the PU films was determined by X-ray photoelectron spectroscopy (XPS) using a VG ESCALAB II electron spectrometer
Table 2. Surface tension of the examined liquids for surface energy determination

\begin{tabular}{|l|c|c|c|c|}
\hline \multicolumn{1}{|c|}{ Liquids } & $\begin{array}{c}\gamma_{\mathbf{L V}} \\
{\left[\mathbf{m J} / \mathbf{m}^{2}\right]}\end{array}$ & $\begin{array}{c}\gamma_{\mathbf{L V}}^{\mathrm{LW}} \\
{\left[\mathbf{m J} / \mathbf{m}^{2}\right]}\end{array}$ & $\begin{array}{c}\gamma_{\mathbf{L V}}^{+} \\
{\left[\mathbf{m J} / \mathbf{m}^{\mathbf{2}}\right]}\end{array}$ & $\begin{array}{c}\gamma_{\mathbf{L V}}^{-} \\
{\left[\mathbf{m J} / \mathbf{m}^{2}\right]}\end{array}$ \\
\hline Distilled water & 72.8 & 21.8 & 25.5 & 25.5 \\
\hline Formamide & 58.0 & 39.0 & 2.28 & 39.6 \\
\hline Diiodomethane & 50.8 & 50.8 & 0 & 0 \\
\hline
\end{tabular}

(East Grinstead, England) under a base pressure of $1 \cdot 10^{-8} \mathrm{~Pa}$. The photoelectron spectra were excited using non-monochromatized $\mathrm{Al} \mathrm{K}_{\alpha}$ radiation $(h v=$ $1486.6 \mathrm{eV}$ ) with a total instrumental resolution of $1 \mathrm{eV}$. The photoelectron spectra were corrected by subtracting a Shirley-type background and were quantified using the peak area and Scofield photoionization cross-sections.

Scanning electron microscopy (SEM) micrographs of the PUs were obtained on a JEOL JSM-6610 instrument (Tokyo, Japan), at a working distance of ca. $14 \mathrm{~mm}$ and an accelerating voltage of $20 \mathrm{kV}$.

Investigation of the surface topography and heterogeneity relief was done by the atomic force microscope (DimensionIcon, Bruker, Santa Barbara, USA), equipped with the SSS-NCL probe, Super Sharp Silicon ${ }^{\mathrm{TM}}$ - SPM-Sensor (NanoSensors ${ }^{\mathrm{TM}}$ Switzerland; spring constant $35 \mathrm{~N} / \mathrm{m}$, resonant frequency $\approx 170 \mathrm{kHz}$ ). Measurements were performed under ambient conditions using the tapping mode AFM technique. The scans covered the sizes of $10 \times$ $10 \mu \mathrm{m}$. The AFM images of the fracture areas of PU films after previous freeze-fracturing at the temperature of liquid were measured in order to evaluate the inner arrangement in the bulk system.

Dynamic mechanical thermal analysis (DMTA) was performed on an ARES G2 rheometer (TA Instruments, New Castle, USA) at a frequency of $1 \mathrm{~Hz}$, strain $0.1 \%$, with a heating rate of $3^{\circ} \mathrm{C} / \mathrm{min}$ and in the temperature range from -135 to $180^{\circ} \mathrm{C}$. The measurements were carried out using rectangular specimens $(15.0 \mathrm{~mm} \times 7.8 \mathrm{~mm} \times 1.0 \mathrm{~mm} \pm 0.2 \mathrm{~mm})$, under torsion mode, using torsion fixture (rectangle) geometry. All details of the calculation of crosslinking density and average molecular weight between two crosslinks using the rubber elasticity theory and calculated from DMTA results, are described in the literature [19-21,33]. Some clarification of the calculation of crosslinking density is given. The crosslinking density of the synthesized PU networks can be calculated from the rubber elasticity theory using Equation (3) and (4): 
$\nu=\frac{G^{\prime}}{R T}$

where $G^{\prime}$ represents rubbery plateau modulus at $T=$ $\left(T_{\mathrm{gHS}}\right)_{\mathrm{G}^{\prime \prime}}+90^{\circ} \mathrm{C},\left(T_{\mathrm{gHS}}\right)_{\mathrm{G}^{\prime \prime}}$ is the glass transition temperature of the hard segments determined from loss modulus $\left(G^{\prime \prime}\right)$ maximum, $T$ is the temperature in Kelvin and $R$ is the universal gas constant. Value of the molecular weight of polymer chain between crosslinks $\left(M_{\mathrm{c}}\right)$ was evaluated as:

$M_{\mathrm{c}}=\frac{\rho_{\mathrm{PU}}}{\nu}$

where $\rho_{\mathrm{PU}}$ is the density of PUs.
Differential scanning calorimetry (DSC) was carried out on a DSC Q1000V9.0 Build 275 thermal analyzer (New Castle, USA). The DSC scans were recorded under a dynamic nitrogen atmosphere (the flow rate of nitrogen was $50 \mathrm{~mL} / \mathrm{min}$ ), in the temperature range from -140 to $230^{\circ} \mathrm{C}$, at a heating and cooling rate of 10 and $5^{\circ} \mathrm{C} / \mathrm{min}$, respectively.

\section{Results and discussion}

\subsection{Synthesis of the PU networks}

Two series of PUs based on Boltorn ${ }^{\circledR}$ hyperbranched polyester of the third pseudo generation, 4,4'-methylenediphenyl diisocyanate and hydroxyethoxy propyl terminated poly(dimethylsiloxane) (samples

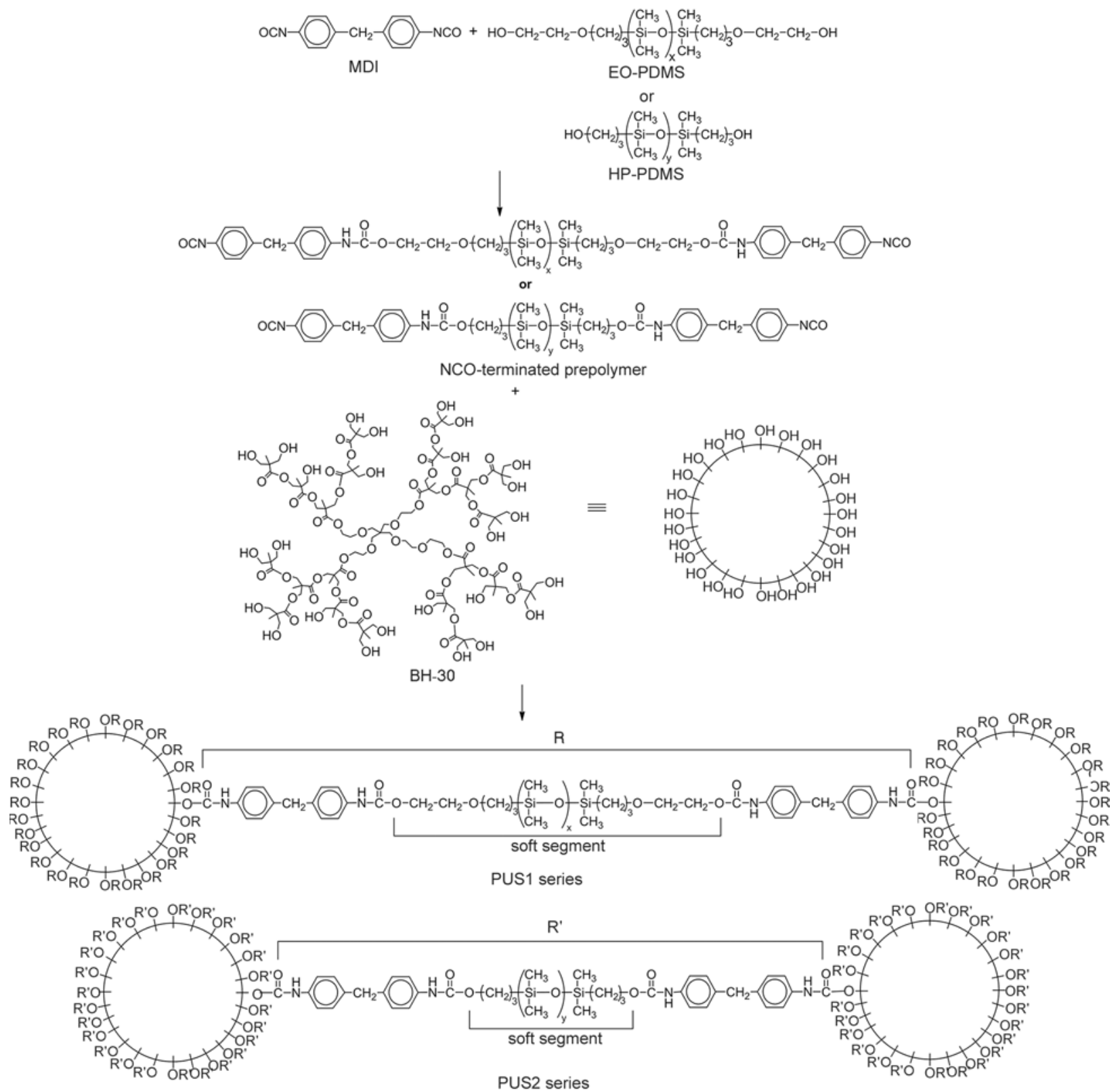

Figure 1. The simplified reaction pathway of the synthesis of PU networks based on EO-PDMS (PUS1 series) and HPPDMS (PUS2 series) 
of the PUS1 series) or hydroxy propyl terminated poly(dimethylsiloxane) (samples of the PUS2 series) were synthesized by a two-step polymerization in solution. In our previous work, PUs were synthesized in melt using BH-20, MDI and two different macrodiols: poly(tetramethylene oxide) and EOPDMS [15]. However, our results showed that the polymerization in melt and incompatibility of nonpolar EO-PDMS with polar reactants, i.e. BH-20 and MDI, led to the formation of heterogeneous PU networks. Therefore, in this work, a two-step polymerization in solution was applied to improve the compatibility between reactants during the synthesis of PUs. The mixture of NMP/THF was used as a reaction medium for the synthesis of PUs. The simplified reaction pathway of the synthesis of PU networks based on EO-PDMS and HP-PDMS is shown in Figure 1.

\subsection{FTIR characterization}

The chemical structure of PUs was investigated by FTIR spectroscopy. In Figure 2, FTIR spectra of the synthesized PUs and the control sample are given. In the FTIR spectrum of the control sample, the presence of urethane-NH groups at $3320 \mathrm{~cm}^{-1}$ can be observed, while the characteristic region at 1700 $1735 \mathrm{~cm}^{-1}$ was ascribed to the carbonyl urethane and ester groups. The amide II and amide III bands appeared at 1547 and $1260 \mathrm{~cm}^{-1}$, respectively. The FTIR absorption bands characteristic for the $\mathrm{C}-\mathrm{O}-\mathrm{C}$ groups $\left(1040\right.$ and $\left.1120 \mathrm{~cm}^{-1}\right)$, aromatic $\mathrm{C}=\mathrm{C}$ linkage (1599 and $1411 \mathrm{~cm}^{-1}$ ) and $-\mathrm{CH}_{2}-$ and $-\mathrm{CH}_{3}$ groups $\left(2900-3000 \mathrm{~cm}^{-1}\right)$ can also be observed in the FTIR spectrum of the control sample.

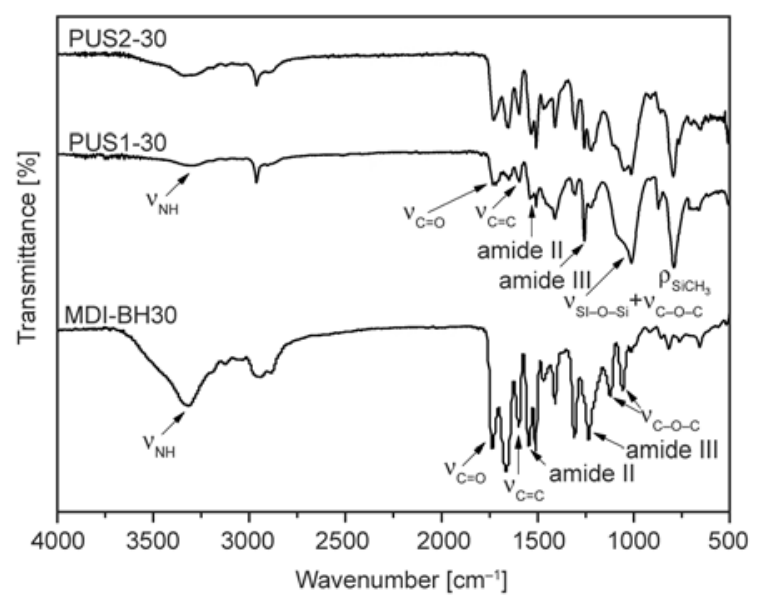

Figure 2. FTIR spectra of the synthesized PUs and the control MDI-BH30 sample
In the FTIR spectra of PUs, peaks corresponding to amide II and amide III vibrations were observed at around 1537 and $1258 \mathrm{~cm}^{-1}$, respectively. The peaks which were ascribed to the $\mathrm{C}=\mathrm{O}$ and $-\mathrm{NH}$ vibrations were detected in the regions $1645-1735 \mathrm{~cm}^{-1}$ and $3100-3500 \mathrm{~cm}^{-1}$, respectively. The absorption bands which were observed at around 1015 and $1080 \mathrm{~cm}^{-1}$ represent overlapped bands of $\mathrm{Si}-\mathrm{O}-\mathrm{Si}$ and $\mathrm{C}-\mathrm{O}-\mathrm{C}$ groups, respectively. The absorption band at around $790 \mathrm{~cm}^{-1}$ was ascribed to the $\mathrm{Si}-\mathrm{CH}_{3}$ linkage. The presence of the symmetric and asymmetric $-\mathrm{CH}_{2}-$ and $-\mathrm{CH}_{3}$ groups was observed at around 2961, 2903 and $2875 \mathrm{~cm}^{-1}$. Other bands at around 1596 and $1412 \mathrm{~cm}^{-1}$ were assigned to the aromatic $C=C$. Since no peak was detected at $2260 \mathrm{~cm}^{-1}$ in the FTIR spectra of these PUs, it can be concluded that all isocyanate groups were incorporated into the polymer chains.

\subsection{Contact angles and surface free energy}

Since the synthesized PUs prepared from the soft PDMS and hard MDI-HBP segments were designed to obtain materials for coating applications, their surface energy and wettability play a key role. The results obtained from contact angle measurements and the surface free energy determinations are presented in Tables 3 and 4. Post-hoc Tukey's HSD test at $95 \%$ confidence limit was calculated to show significant differences between different samples. The surface energy of the synthesized PUs and control sample is shown in Figure 3.

The water contact angles of PUS2 series were higher than values obtained for samples from PUS1 series. Therefore, the synthesized PUs based on HP-PDMS were more hydrophobic, i.e. had better waterproof properties than PUs based on EO-PDMS. From the results, it is also quite apparent that the synthesized PUs had higher water contact angles than the con-

Table 3. Water contact angle, $\theta_{1}$, formamide contact angle, $\theta_{2}$, and diiodomethane contact angle, $\theta_{3}$, of the synthesized PUs and control sample

\begin{tabular}{|l|c|c|c|}
\hline \multicolumn{1}{|c|}{ Sample } & $\begin{array}{c}\boldsymbol{\theta}_{\mathbf{1}} \\
{\left[{ }^{\circ}{ }^{\circ}\right.}\end{array}$ & $\begin{array}{c}\boldsymbol{\theta}_{\mathbf{2}} \\
{\left[^{\circ}{ }^{\circ}\right.}\end{array}$ & $\begin{array}{c}\boldsymbol{\theta}_{\mathbf{3}} \\
{\left[{ }^{\circ}\right]}\end{array}$ \\
\hline PUS1-15 & $86.23 \pm 0.90^{\mathrm{a}}$ & $67.75 \pm 0.85^{\mathrm{c}}$ & $49.50 \pm 0.95^{\mathrm{c}}$ \\
\hline PUS1-30 & $86.78 \pm 0.79^{\mathrm{ab}}$ & $75.88 \pm 1.45^{\mathrm{a}}$ & $51.73 \pm 0.79^{\mathrm{a}}$ \\
\hline PUS2-15 & $88.13 \pm 0.46^{\mathrm{bc}}$ & $74.33 \pm 0.51^{\mathrm{a}}$ & $52.40 \pm 0.48^{\mathrm{a}}$ \\
\hline PUS2-30 & $89.53 \pm 0.92^{\mathrm{c}}$ & $79.70 \pm 0.75^{\mathrm{d}}$ & $56.05 \pm 0.56^{\mathrm{d}}$ \\
\hline MDI-BH30 & $74.68 \pm 0.75^{\mathrm{d}}$ & $62.98 \pm 0.72^{\mathrm{b}}$ & $34.50 \pm 0.59^{\mathrm{b}}$ \\
\hline
\end{tabular}

a,b,c,d Different letters printed in superscript within the same column show significantly different means of observed data (at $p<$ 0.05 level, according to post-hoc Tukey's HSD test) 
Table 4. Surface free energy and its components of the synthesized PUs and control sample

\begin{tabular}{|l|c|c|c|c|c|}
\hline \multicolumn{1}{|c|}{ Sample } & $\begin{array}{c}\gamma_{\mathbf{S}}^{\mathbf{L B}} \\
{\left[\mathbf{m J} / \mathbf{m}^{2}\right]}\end{array}$ & $\begin{array}{c}\gamma_{\mathbf{S}}^{\mathbf{A B}} \\
{\left[\mathbf{m J} / \mathbf{m}^{2}\right]}\end{array}$ & $\begin{array}{c}\gamma_{\mathbf{S}}^{+} \\
{\left[\mathbf{m J} / \mathbf{m}^{2}\right]}\end{array}$ & $\begin{array}{c}\gamma_{\mathbf{S}}^{-} \\
{\left[\mathbf{m J} / \mathbf{m}^{2}\right]}\end{array}$ & $\begin{array}{c}\gamma_{\mathbf{s}(\text { total) }} \\
{\left[\mathbf{m J} / \mathbf{m}^{2}\right]}\end{array}$ \\
\hline PUS1-15 & $34.55 \pm 0.53^{\mathrm{c}}$ & $2.07 \pm 0.14^{\mathrm{b}}$ & $1.91 \pm 0.14^{\mathrm{b}}$ & $3.97 \pm 0.15^{\mathrm{b}}$ & $38.52 \pm 0.58^{\mathrm{ab}}$ \\
\hline PUS1-30 & $33.30 \pm 0.45^{\mathrm{a}}$ & $2.89 \pm 0.18^{\mathrm{a}}$ & $2.83 \pm 0.24^{\mathrm{a}}$ & $5.72 \pm 0.38^{\mathrm{a}}$ & $39.03 \pm 0.52^{\mathrm{b}}$ \\
\hline PUS2-15 & $32.92 \pm 0.27^{\mathrm{a}}$ & $2.55 \pm 0.05^{\mathrm{c}}$ & $2.29 \pm 0.08^{\mathrm{c}}$ & $4.83 \pm 0.06^{\mathrm{c}}$ & $37.75 \pm 0.24^{\mathrm{a}}$ \\
\hline PUS2-30 & $30.84 \pm 0.32^{\mathrm{b}}$ & $2.86 \pm 0.07^{\mathrm{a}}$ & $2.70 \pm 0.14^{\mathrm{a}}$ & $5.55 \pm 0.09^{\mathrm{a}}$ & $36.39 \pm 0.34^{\mathrm{c}}$ \\
\hline MDI-BH30 & $42.25 \pm 0.27^{\mathrm{d}}$ & $3.21 \pm 0.13^{\mathrm{d}}$ & $4.19 \pm 0.16^{\mathrm{d}}$ & $7.33 \pm 0.21^{\mathrm{d}}$ & $49.59 \pm 0.46^{\mathrm{d}}$ \\
\hline
\end{tabular}

a,b,c,d Different letters printed in superscript within the same column show significantly different means of observed data (at $p<0.05$ level, according to post-hoc Tukey's HSD test)

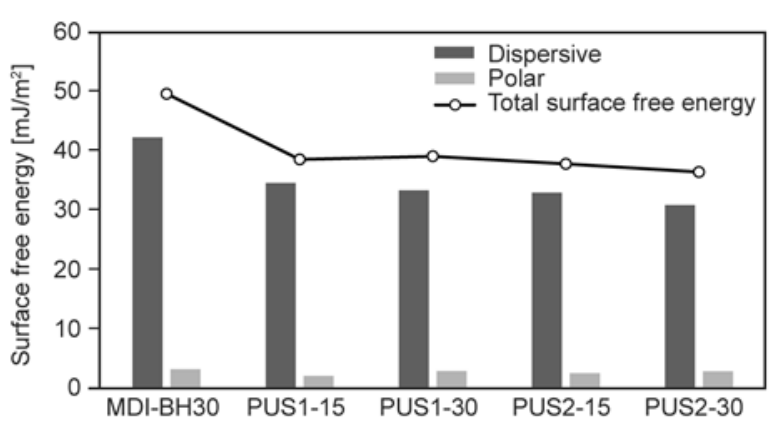

Figure 3. Surface free energy of the synthesized PUs and control MDI-BH30 sample

trol sample. This behavior may be ascribed to the tendency of the PDMS segments to migrate to the surface, due to the very low surface energy of PDMS, resulting in a part of the PU surfaces being covered by PDMS [31]. As can be seen (Table 3), the change of the formamide and diiodomethane contact angles of PU samples followed the same trend as the water contact angle.

According to the Figure 3, the surface free energy of the samples based on HP-PDMS was lower than that of samples based on EO-PDMS. The dispersive component decreased, but the polar component did not vary for the PUs based on HP-PDMS. The synthesized PU samples had lower values of surface energy compared to the control sample (Table 4). Furthermore, the surface energy values of our PU samples were higher than values presented in the literature for siloxane-urethane coatings (around $25 \mathrm{~mJ} / \mathrm{m}^{2}$ ) [34] and linear high molecular weight PDMS $\left(21 \mathrm{~mJ} / \mathrm{m}^{2}\right)$ [35]. In contrast, the surface free energy values of our newly-synthesized PUs were closer to that of the control MDI-BH30 sample $\left(49.6 \mathrm{~mJ} / \mathrm{m}^{2}\right)$. These results indicated that PDMS covers only a part of the surface of these novel PUs. Therefore, surface energy studies have confirmed the presence of both hydrophobic PDMS and hydrophilic urethane groups at the surface, giving a slight amphiphilic character to the surface of the PU samples.
The water contact angle of PUs was higher but the surface free energy was lower than the values obtained for previously synthesized PU networks based on EO-PDMS and hyperbranched polyester of the fourth pseudo generation $\left(\theta_{1}=82.6-87.3^{\circ}\right.$ and $\left.\gamma_{\mathrm{s}(\text { total })}=38.7-43.8 \mathrm{~mJ} / \mathrm{m}^{2}\right)[21]$.

\subsection{XPS analysis}

XPS investigation was conducted to provide information of surface elemental composition of PU networks. Figure 4 shows XPS survey spectra and high resolution XPS spectra of the PU films.

The surface elemental composition, calculated from the normalized peak areas of $\mathrm{C} 1 \mathrm{~s}, \mathrm{O} 1 \mathrm{~s}, \mathrm{~N} 1 \mathrm{~s}$ and Si $2 p$ core level peaks, is listed in Table 5 . The surface content of $\mathrm{Si}$ is almost constant for most PU samples, excluding PUS1-30. This sample has also a higher concentration of carbon and nitrogen at surface. Probably, the reason for this is the presence of more urethane -NH groups. The content of nitrogen for other PU samples is at the XPS sensitivity limit.

The C1s spectra of all PU samples contain peak centered at $284.8 \mathrm{eV}$, attributed to $\mathrm{C}-\mathrm{C}$ and $\mathrm{C}-\mathrm{H}$ bonds in the polyurethane. Only for PUS1-30 sample the $\mathrm{C} 1 \mathrm{~s}$ peak shows asymmetry at a higher binding energy side at $\sim 286.5 \mathrm{eV}$. According to the literature data, this feature could be assigned to the carbon formed $\mathrm{C}-\mathrm{O}$ bonding [36]. The measured Si2p binding energy for all PU samples at $102.3 \mathrm{eV}$ is consistent with previously published values for PDMS materials $[36,37]$. The binding energy of the N1s

Table 5. XPS data of surface composition of the synthesized PUs

\begin{tabular}{|l|c|c|c|c|}
\hline \multirow{2}{*}{ Sample } & \multicolumn{4}{|c|}{ Surface concentration [atomic\%] } \\
\cline { 2 - 5 } & $\mathbf{C}$ & $\mathbf{O}$ & $\mathbf{N}$ & Si \\
\hline PUS1-15 & 50.2 & 24.9 & 0.2 & 24.7 \\
\hline PUS1-30 & 59.2 & 22.8 & 2.2 & 15.8 \\
\hline PUS2-15 & 51.0 & 24.5 & 0.4 & 24.1 \\
\hline PUS2-30 & 50.6 & 24.1 & 0.3 & 25.0 \\
\hline
\end{tabular}



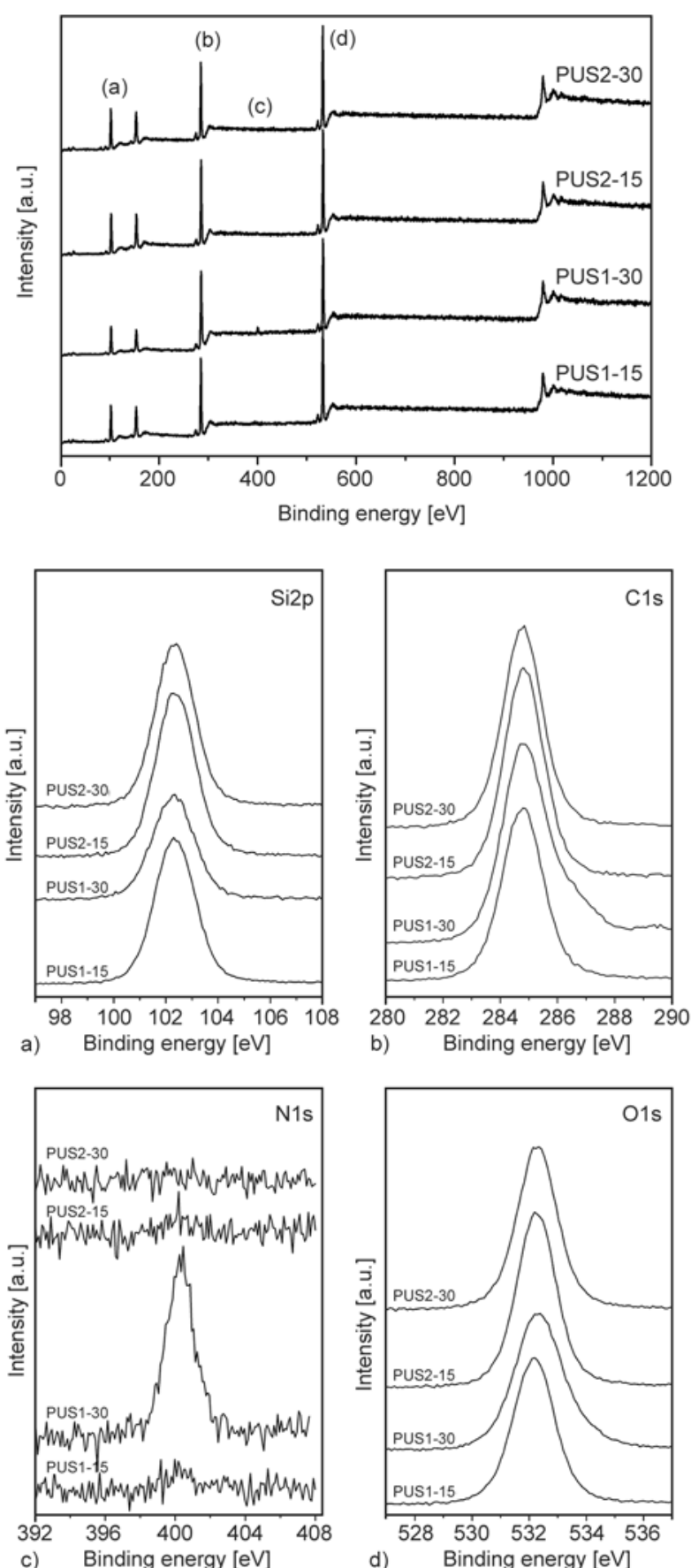

Figure 4. XPS survey spectra and high resolution XPS spectra of PUS1-15, PUS1-30, PUS2-15 and PUS2-30 films: (a) Si2p; (b) C1s; (c) N1s; (d) O1s

peak of the PUS1-30 sample at $400.4 \mathrm{eV}$ is typical for urethane $-\mathrm{NH}$ bonds.

The obtained results showed tendency of PDMS segments to migrate to the PU surface. It stemmed from the silico-organic groups with low surface energy, incompatibility with polyurethane and high chain flexibility, which allowed it's migration to the surface of PU films [37]. This result was in good agreement with that from the contact angle analysis. On the other hand, the $\mathrm{N}$ concentration on the surface was very low, indicating that the urethane hard segments of samples PUS1-15, PUS2-15 and PUS2-30 were present in a small amount on their surface, except for PUS1-30.

\subsection{Morphological investigation by SEM}

The surface morphology of PU networks was analyzed by SEM and the obtained microphotographs are shown in Figure 5. The results obtained by SEM analysis revealed the existence of microphase separated morphology of the investigated PUs. Figure 5 shows a typical view of microdomains of hard MDIHBP segments, hydrogen-bonded in aggregates and irregular in shapes, and unevenly dispersed in the soft PDMS matrix of the PUs, which was consistent with the results for PDMS based PUs [38]. Therefore, the brighter region in the surface view of the PUs represents the aggregates of hard segments in the darker PDMS soft segments that are more pronounced for samples with high soft segment content. This might be because the samples PUS1-30 and PUS2-30 have higher crosslinking density in comparison with PUS1-15 and PUS2-15 (Table 7). With the increase of crosslinking density, there was stronger cohesion force among hard segment chains, leading to an inclination of hard segments aggregation within soft phase. SEM results of the samples PUS1-15 and PUS2-15 indicate increased homogeneity in samples and improved compatibility of all components in comparison to PUS1-30 and PUS2-30.

\subsection{AFM an alysis}

In order to understand the influence of the type of PDMS soft segments on the formation of surface topography and heterogeneity relief of PUs, AFM analysis was performed. The obtained results are shown in Figures 6 and 7 and summarized in Table 6. Based on prior studies, it is known that the bright regions represent the hard phase (hard domains), while the darker regions represent the soft phase in a polyurethane.

Height images, showing surface topography, substantially differ for the synthesized PUs: the topographies of PUS1-15 and PUS1-30 display particulate formations of nm size, while PUS2-15 and PUS230 samples show agglomerates of $\mu \mathrm{m}$ size (PUS215 is the roughest one). In comparison with samples from PUS1 series, the roughness of PUS2 samples is higher (see Table 6). In addition, the three-dimen- 


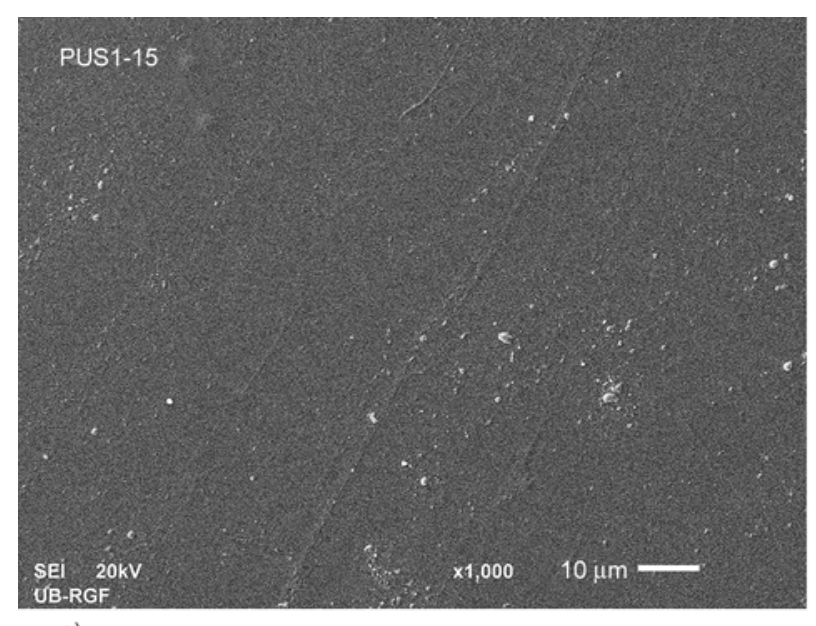

a)

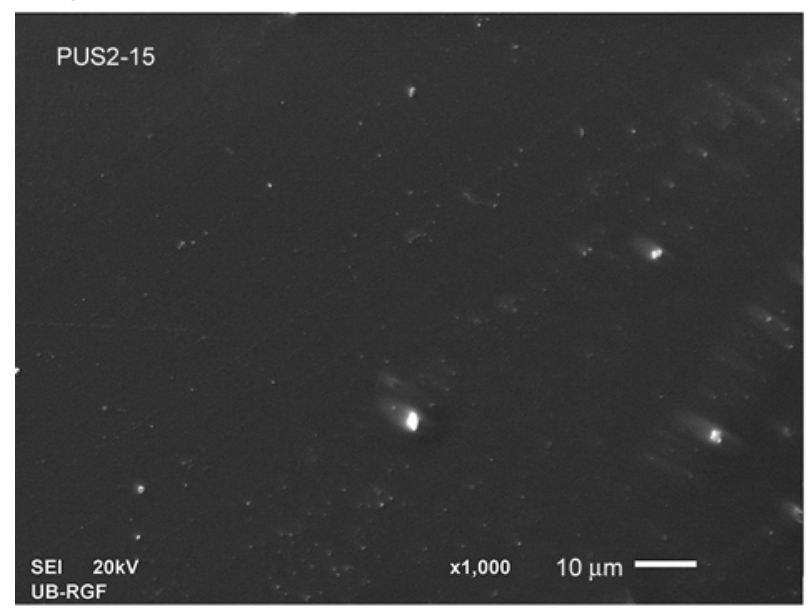

c)

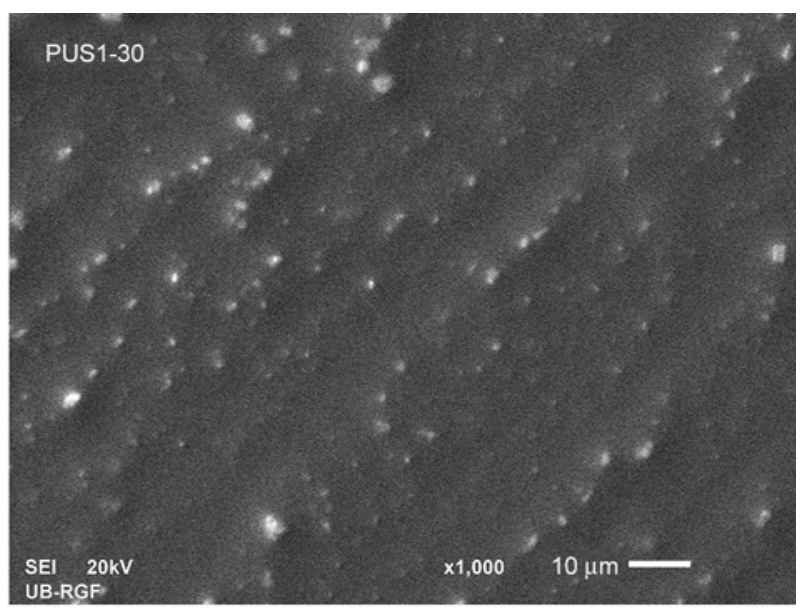

b)

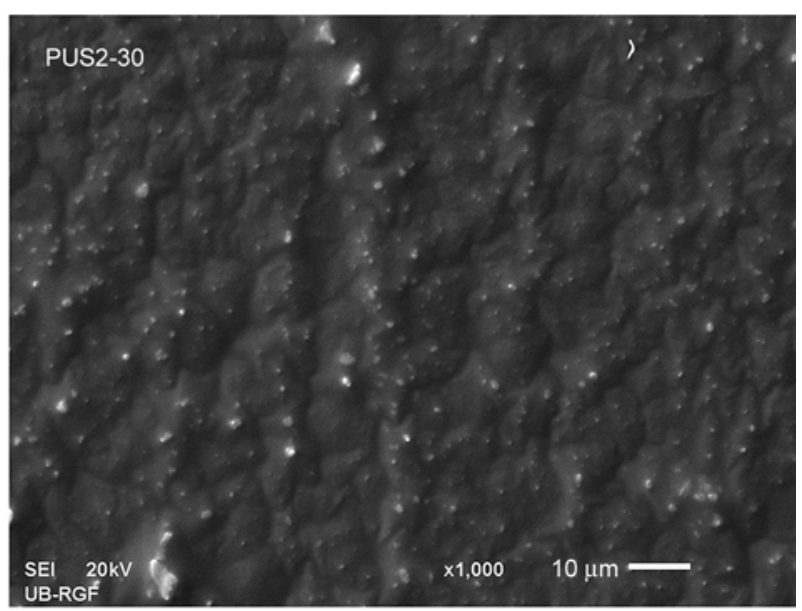

d)

Figure 5. SEM microphotographs of the surface of the synthesized PUs: (a) PUS1-15, (b) PUS1-30, (c) PUS2-15, (d) PUS2-30

Table 6. Roughness values of the synthesized PUs

\begin{tabular}{|l|c|c|c|c|}
\hline Sample & $\begin{array}{c}\text { Surface area } \\
{\left[\boldsymbol{\mu m}^{2}\right]}\end{array}$ & $\begin{array}{c}\mathbf{R}_{\mathbf{q}}{ }^{*} \\
{[\mathbf{n m}]}\end{array}$ & $\begin{array}{c}\mathbf{R}_{\mathbf{a}}{ }^{* * *} \\
{[\mathbf{n m}]}\end{array}$ & $\begin{array}{c}\mathbf{R}_{\mathbf{m a x}}{ }^{* * * *} \\
{[\mathbf{n m}]}\end{array}$ \\
\hline PUS1-15 & 106 & 104 & 128 & 1818 \\
\hline PUS1-30 & 104 & 101 & 77 & 670 \\
\hline PUS2-15 & 131 & 839 & 663 & 4143 \\
\hline PUS2-30 & 120 & 385 & 294 & 2533 \\
\hline
\end{tabular}

Surface area: the total area of examined sample surface (the threedimensioned area of a given region expressed as the sum of the area of all the triangles formed by three adjacent data points). $R_{\mathrm{q}}^{*}\left(R_{\mathrm{ms}}\right)$ : the standard deviation of the $Z$ values within the given area

$R_{\mathrm{a}}{ }^{* *}$ (mean roughness) the mean value of the surface relative to the center place

$R_{\max }^{* * *}$ (max height): the difference in height between the highest and lowest points on the surface relative to the mean plane Mean: the average of all $Z$ values within the enclosed area.

sional large-scale resolution images clearly show that the surface structure changes and the roughness diminishes with increasing content of the PDMS soft segments. These results are in agreement with those previously reported, based on surface composition analysis, which showed that PDMS predominates on the surface of block copolymers contaning PDMS segments due to its immiscibility with other polymers and its low surface energy [39].

Phase images (i.e., maps of tip-sample interactions) enable qualitative insight into the sample homogeneity relief. The synthesized PUs are characterized by two-phase morphology consisting of a hard segment-rich phase and a soft segment-rich phase. It is evident that the synthesized PU samples are distinguished by heterogeneous character, apparently connected with strong microphase separation. The obtained results showed that the synthesized samples are heterogeneous on nm (PUS1-15) or even on $\mu \mathrm{m}$ level (PUS1-30, PUS2-15 and PUS2-30). Samples PUS1-15, PUS2-15 and PUS2-30 have very sharp interface between both phases, characterized entirely black and/or white localities anticipating strong microphase separation. On the other hand, the phase image of sample PUS1-30 contains also relatively 


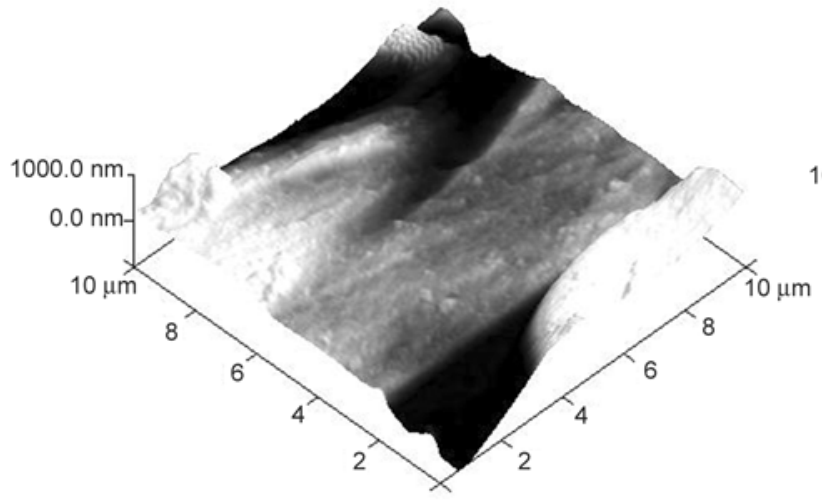

a)

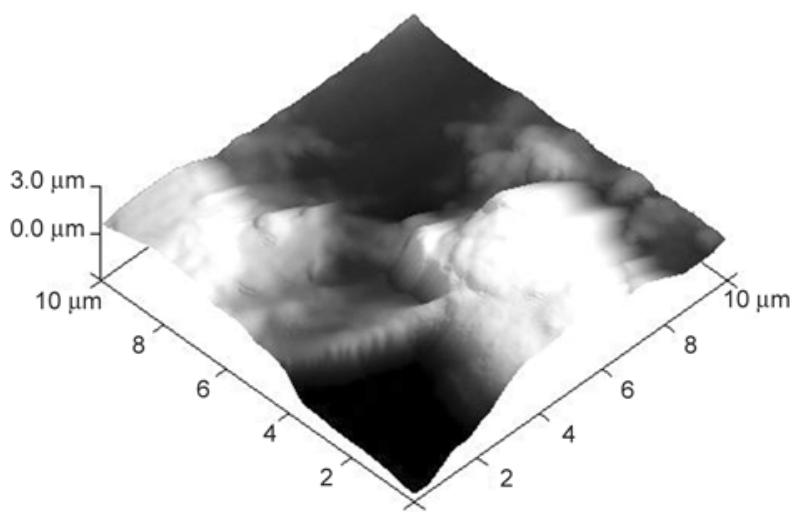

c)
PUS1-15

PUS2-15

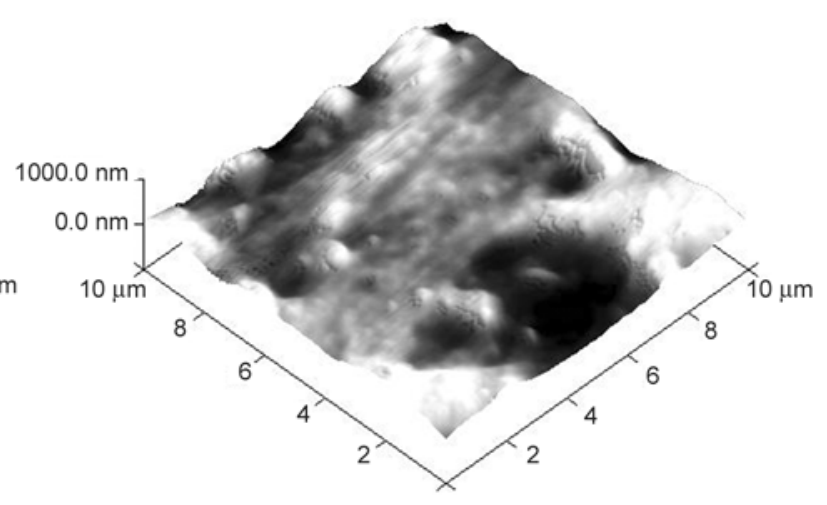

b) PUS1-30

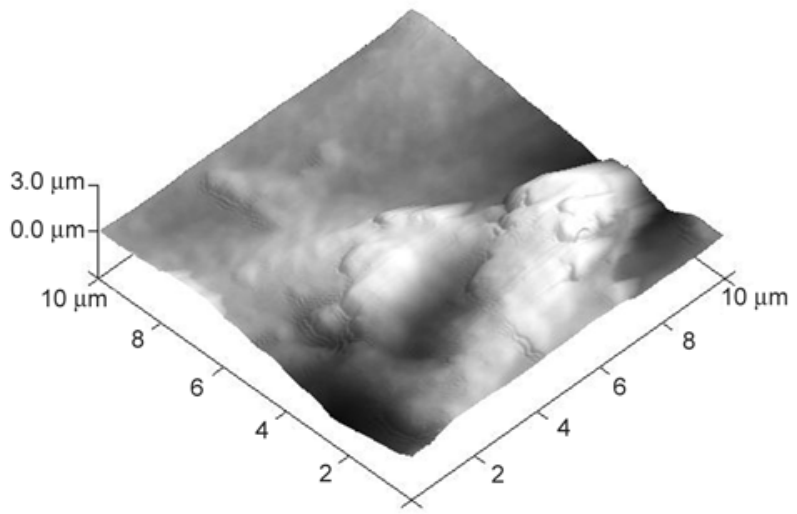

d)

PUS2-30

Figure 6. 3D AFM height images of the fractured surface of the synthesized PUs: (a) PUS1-15, (b) PUS1-30, (c) PUS2-15, (d) PUS2-30

Table 7. Glass transition temperatures determined by DSC, temperatures corresponding to the tan $\delta$ maximum, crosslinking density, $v$, and molecular weight of polymer chain between crosslinks, $M_{\mathrm{c}}$, determined by DMTA of the synthesized PUs

\begin{tabular}{|c|c|c|c|c|c|c|c|}
\hline \multirow[b]{2}{*}{ Sample } & \multirow[b]{2}{*}{$\begin{array}{c}\mathrm{T}_{\mathrm{gSS}}(\mathrm{DSC}) \\
{\left[{ }^{\circ} \mathrm{C}\right]}\end{array}$} & \multirow[b]{2}{*}{$\begin{array}{c}\mathbf{T}_{\mathrm{gHS}}(\mathrm{DSC}) \\
{\left[{ }^{\circ} \mathrm{C}\right]}\end{array}$} & \multicolumn{3}{|c|}{$\tan \delta$} & \multirow[b]{2}{*}{$\begin{array}{c}\mathrm{v} \cdot 10^{4} \\
{\left[\mathrm{~mol} / \mathrm{cm}^{3}\right]}\end{array}$} & \multirow[b]{2}{*}{$\begin{array}{c}\mathbf{M}_{\mathbf{c}} \\
{[\mathrm{g} / \mathrm{mol}]}\end{array}$} \\
\hline & & & $\begin{array}{l}\mathbf{T}_{\mathbf{g S S}} \\
{\left[{ }^{\circ} \mathbf{C}\right]}\end{array}$ & $\begin{array}{c}\mathbf{T}_{2} \\
{\left[{ }^{\circ} \mathbf{C}\right]}\end{array}$ & $\begin{array}{l}\mathbf{T}_{\mathrm{gHS}} \\
{\left[{ }^{\circ} \mathrm{C}\right]}\end{array}$ & & \\
\hline PUS1-15 & -123 & 50 & -125 & -74 & 45 & 10.61 & 1000 \\
\hline PUS1-30 & -125 & 57 & -126 & -67 & $50 / 73$ & 14.32 & 800 \\
\hline PUS2-15 & -124 & 52 & -126 & -79 & 70 & 14.21 & 780 \\
\hline PUS2-30 & -121 & 63 & -118 & -58 & 84 & 103.5 & 110 \\
\hline
\end{tabular}

high part of grey color indicating higher degree of phase mixing compared with samples PUS1-15, PUS2-15 and PUS2-30.

\subsection{DMTA and DSC analysis}

Dynamic mechanical thermal measurements were used to examine viscoelastic properties of PU samples. The mechanical loss factor, $\tan \delta$, storage modulus, $G^{\prime}$, and loss modulus, $G^{\prime \prime}$, of the synthesized PUs are shown in Figures 8 and 9. The PUs exhibited two thermal transitions and probably one sec- ond relaxation process [13]. The glass transition temperatures of PU networks were affected by the crosslinking density, plus the type and content of soft segment. The values of glass transition temperatures, obtained as the temperature of the $\tan \delta$ maximum, are shown in Table 7. Temperatures of $\tan \delta$ peaks are somewhat higher than temperatures corresponding to the $G^{\prime \prime}$ peaks.

The glass transition temperature in the range from -118 to $-126^{\circ} \mathrm{C}$ is associated with the soft PDMS segment ( $\left.T_{\mathrm{gSS}}\right)$. Tan $\delta$ curves show a small maxi- 

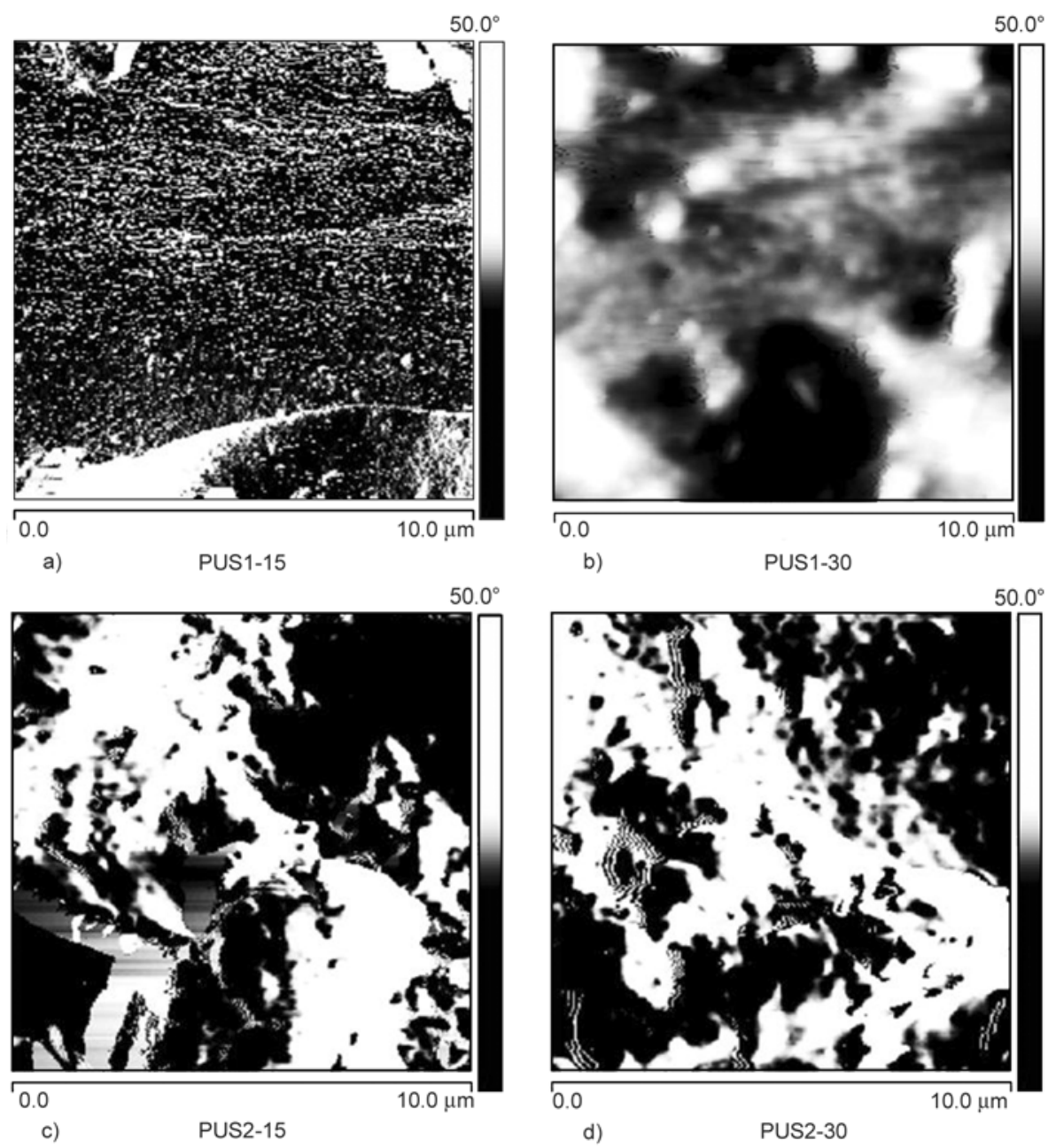

Figure 7. 2D AFM phase images of the fractured surface of the synthesized PUs: (a) PUS1-15, (b) PUS1-30, (c) PUS2-15, (d) PUS2-30

mum at -74 and $-67^{\circ} \mathrm{C}$ for PUS1-15 and PUS1-30 samples, and at -79 and $-58^{\circ} \mathrm{C}$ for PUS2-15 and PUS2-30 samples, respectively, that may be corresponding to the subglass relaxation process $\left(T_{2}\right)$, but this should be studied further. This is probably a consequence of the movement of the part of chain which contains urethane groups connected to the hyperbranched polyester according to the findings of other authors [13]. Due to the steric hindrance, these urethane groups are not involved in the formation of hydrogen bonds and are therefore, more mobile. The samples from the PUS2 series had higher values of $T_{\mathrm{gHS}}$ than the samples from the PUS1 series. The presence of terminal ethoxy units in PDMS prepolymer improves miscibility between reactants and, therefore, the PU samples based on EO-PDMS (PUS1 series) had lower $T_{\mathrm{gHS}}$ values, and consequently, lower degree of microphase separation. The glass transition temperatures of the hard and soft segments were also determined in DSC thermo-

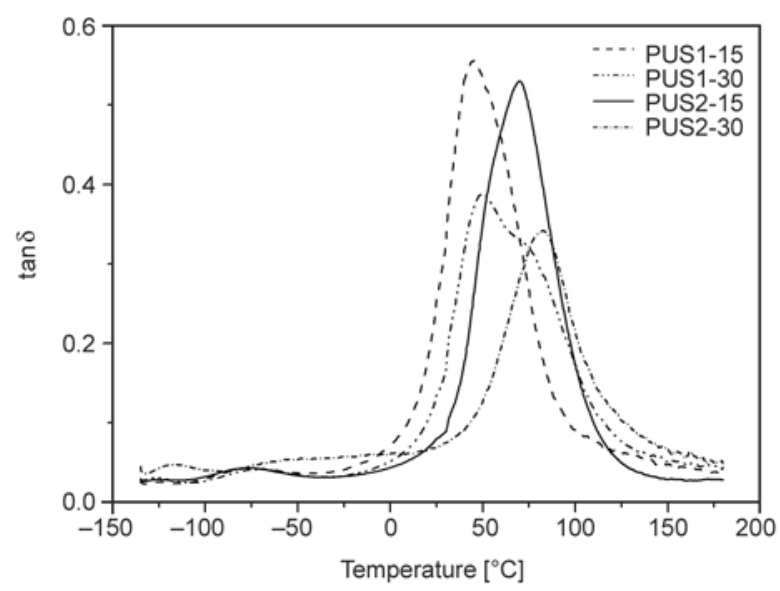

Figure 8. Tan $\delta$ of the synthesized PUs versus temperature

grams of the synthesized PUs (Table 7). The observed trend for $T_{\mathrm{gHS}}$ values was consistent with DMTA results. The $T_{\mathrm{g}}$ of the PDMS soft segments of the synthesized PUs was between -121 and $-125^{\circ} \mathrm{C}$. The $T_{\mathrm{gSS}}$ values determined as $(\tan \delta)_{\max }$ from DMTA curves are slightly higher than those determined by 

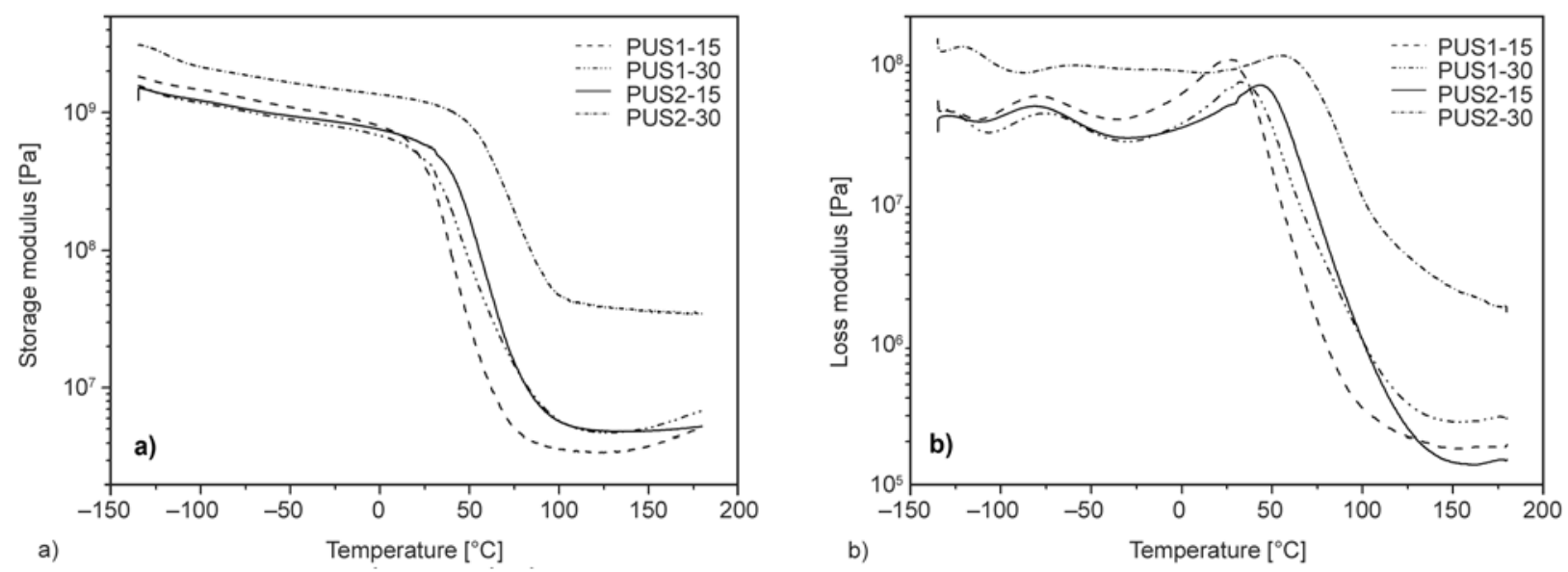

Figure 9. (a) Storage modulus and (b) loss modulus of the synthesized PUs versus temperature

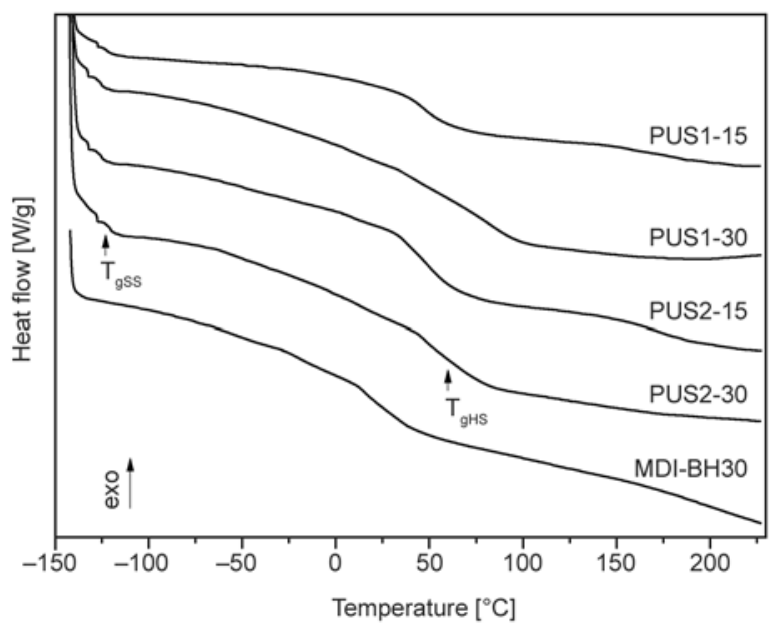

Figure 10. DSC thermograms of the synthesized PUs and control MDI-BH30 sample

DSC. DSC thermograms of the synthesized PUs and control sample, determined from the second heating run, are shown in Figure 10. A $T_{\mathrm{g}}$ value of the control MDI-BH30 sample obtained by DSC analysis was $30^{\circ} \mathrm{C}$, which shifted to lower temperature compared with that of the synthesized PUs. The synthesized samples based on PDMS have two $T_{\mathrm{g}}$ in comparison with the control sample and therefore possess microphase separated structure.

The network homogeneity of each of the PU networks was analyzed by comparing the width of the mechanical loss factor curves [14, 40, 41]. The width of the $\tan \delta$ peak for samples PUS2-15 and PUS230 was slightly lower in comparison with PUS1-15 and PUS1-30 samples. The slightly wider peak of $\tan \delta$ obtained for PUS1 samples indicates a less homogeneous distribution of crosslinks than for the samples of PUS2 series.

For PU samples, the storage modulus firstly decreased gradually, and then decreased relatively fast at temperatures between 20 to $100^{\circ} \mathrm{C}$. A rubber elastic plateau was observed at around $120^{\circ} \mathrm{C}$ for all examined PUs. PU samples based on HP-PDMS had higher $G^{\prime}$ in the rubbery plateau than the samples based on EO-PDMS (Figure 9), which indicates the higher crosslinking density (Table 7). The results given in Table 7 show that the crosslinking density of PUs based on HP-PDMS was higher, while $M_{\mathrm{c}}$ was lower than values obtained for the EO-PDMS containing PUs. Samples PUS1-30 and PUS2-30 have higher values of the crosslinking density in comparison with PUS1-15 and PUS2-15, and PUS2-30 has the highest crosslinking density of all samples. The reason for higher crosslinking density of PUS1-30 and PUS2-30 samples in comparison with samples PUS1-15 and PUS2-15 may be steric hindrance caused by HBP molecules which is more pronounced in samples with $15 \mathrm{wt} \%$ of soft segment because of the greatest amount of BH-30. Therefore, instead of participating in the reaction of crosslinking, $-\mathrm{OH}$ groups of the HBP may be hydrogen bonded. The obtained results also showed that hydroxypropyl terminated PDMS is more efficiently incorporated in the polyurethane networks in comparison with hydroxyethoxy propyl terminated PDMS.

It can be observed (Figure 9a) that the rubbery plateau modulus of the investigated PU networks was higher than values of the order of $106 \mathrm{~Pa}$ obtained for other crosslinked PUs based on hydroxybutyl-PDMS [42] and based on poly(propylene oxide) or hyperbranched polyester [14]. Therefore, the incorporation of the PDMS macrodiols into PU networks based on $\mathrm{BH}-30$ as the crosslinker improved the thermomechanical and surface properties of the synthesized PUs. 


\section{Conclusions}

Polyurethane networks based on different PDMS macrodiols and hyperbranched polyester of the third pseudo generation were synthesized using two-step polymerization in solution. The results clearly demonstrated that the type of the PDMS macrodiols incorporated in the PUs influenced the morphology, surface and thermomechanical properties of the synthesized PU networks. DMTA showed that the synthesized PU networks based on EOPDMS or HP-PDMS have two glass transition temperatures and a microphase separated structure. Microphase separation, where the hard MDI-HBP domains are dispersed in a soft matrix, was also confirmed by SEM and AFM analyses. Better thermomechanical properties, higher crosslinking density, more hydrophobicity and better waterproof properties were obtained for PU samples based on HP-PDMS than for EO-PDMS-based PUs. The surface energy values of the samples based on HPPDMS were lower than values obtained for the samples based on EO-PDMS. Evaluation of all synthesized PU samples also revealed that their surface energy values were closer to the value obtained for the control sample prepared without PDMS macrodiol and were higher than those of siloxane-urethane coatings and linear PDMS presented in the literature. The obtained results showed the presence of both the hydrophobic PDMS and hydrophilic urethane groups at the surface, giving a slight amphiphilic nature to the surface of the synthesized PUs. The results in this study clearly demonstrate that the synthesis of polyurethanes based on PDMS and hyperbranched polyester leads to the creation of networks with improved surface and thermomechanical properties, which can be easily tailored by changing the type of soft PDMS segment for specific applications.

\section{Acknowledgements}

This work was financially supported by the Ministry of Education, Science and Technological Development of the Republic of Serbia (Project No. 172062) and Czech Science Foundation (GACR, Project No. P108/10/0195). The authors thank Prof. Dr Petar Jovančić (Faculty of Technology and Metallurgy, University of Belgrade) for making instruments for contact angle measurements available.

\section{References}

[1] Dodge J.: Synthesis methods in step-growth polymers. Wiley, New Jersey (2003).

[2] Chattopadhyay D. K., Raju K. V. S. N.: Structural engineering of polyurethane coatings for high performance applications. Progress in Polymer Science, 32, 352418 (2007).

DOI: 10.1016/j.progpolymsci.2006.05.003

[3] Kazmierczak M. E., Fornes R. E., Buchanan D. R., Gilbert R. D.: Investigations of a series of PPDI-based polyurethane block copolymers. II. Annealing effects. Journal of Polymer Science Part B: Polymer Physics, 27, 2189-2202 (1989).

DOI: $10.1002 /$ polb.1989.090271103

[4] Mishra A. K., Narayan R., Raju K. V. S. N., Aminabhavi T. A.: Hyperbranched polyurethane (HBPU)-urea and HBPU-imide coatings: Effect of chain extender and $\mathrm{NCO} / \mathrm{OH}$ ratio on their properties. Progress in Organic Coatings, 74, 134-141 (2012).

DOI: $10.1016 /$ j.porgcoat.2011.11.027

[5] Mahesh K. P. O., Alagar M., Kumar S. A.: Mechanical, thermal and morphological behavior of bismaleimide modified polyurethane-epoxy IPN matrices. Polymers for Advanced Technologies, 14, 137-146 (2003). DOI: 10.1002/pat.341

[6] Rahman M. M., Chun H. H., Park H.: Waterborne polysiloxane-urethane-urea for potential marine coatings. Journal of Coatings Technology and Research, 8, 389399 (2011).

DOI: $10.1007 / \mathrm{s} 11998-010-9307-9$

[7] Lee Y-H., Kim E-J., Kim H-D.: Synthesis and properties of waterborne poly(urethane urea)s containing polydimethylsiloxane. Journal of Applied Polymer Science, 120, 212-219 (2011).

DOI: 10.1002/app.33007

[8] Yilgör I., McGrath J.: Polysiloxane containing copolymers: A survey of recent developments. Advances in Polymer Science, 86, 1-86 (1988).

DOI: $10.1007 / \mathrm{BFb} 0025274$

[9] Dvornić P. R., Lenz R. W.: High temperature siloxane elastomers. Hüthing Wepf, Heidelberg (1990).

[10] Bokobza L., Diop A. L.: Reinforcement of poly (dimethylsiloxane) by sol-gel in situ generated silica and titania particles. Express Polymer Letters, 4, 355363 (2010).

DOI: $10.3144 /$ expresspolymlett.2010.45

[11] Žagar E., Žigon M.: Aliphatic hyperbranched polyesters based on 2,2-bis(methylol)propionic acid - Determination of structure, solution and bulk properties. Progress in Polymer Science, 36, 53-88 (2011). DOI: 10.1016/j.progpolymsci.2010.08.004

[12] Maji P. K., Bhowmick A. K.: Influence of number of functional groups of hyperbranched polyol on cure kinetics and physical properties of polyurethanes. Journal of Polymer Science Part A: Polymer Chemistry, 47, 731-745 (2009).

DOI: $10.1002 /$ pola.23185 
[13] Czech P., Okrasa L., Ulanski J., Boiteux G., Mechin F., Cassagnau P.: Studies of the molecular dynamics in polyurethane networks with hyperbranched crosslinkers of different coordination numbers. Journal of Applied Polymer Science, 105, 89-98 (2007).

DOI: $10.1002 /$ app. 26106

[14] Asif A., Shi W., Shen X., Nie K.: Physical and thermal properties of UV curable waterborne polyurethane dispersions incorporating hyperbranched aliphatic polyester of varying generation number. Polymer, 46, 11066-11078 (2005). DOI: 10.1016/j.polymer.2005.09.046

[15] Vuković J., Pergal M., Jovanović S., Vodnik V.: Crosslinked polyurethanes based on hyperbranched polymers. Hemijska Industrija, 62, 353-359 (2008). DOI: 10.2298/HEMIND0806353V

[16] Pergal M. V., Džunuzović J. V., Kićanović M., Vodnik V., Pergal M. M., Jovanović S.: Thermal properties of poly(urethane-ester-siloxane)s based on hyperbranched polyester. Russian Journal of Physical Chemistry A, 85, 2251-2256 (2011). DOI: $10.1134 / \mathrm{S} 0036024411130243$

[17] Džunuzović J. V., Pergal M. V., Jovanović S., Vodnik V. V.: Synthesis and swelling behavior of polyurethane networks based on hyperbranched polymer. Hemijska Industrija, 65, 637-644 (2011).

DOI: 10.2298/HEMIND110902071D

[18] Pergal M. V., Džunuzović J. V., Ostojić S., Pergal M. M., Radulović A., Jovanović S.: Poly(urethane-siloxane)s based on hyperbranched polyester as crosslinking agent: Synthesis and characterization. Journal of the Serbian Chemical Society, 77, 919-935 (2012). DOI: 10.2298/JSC111013006P

[19] Džunuzović J. V., Pergal M. V., Poręba R., Ostojić S., Lazić N., Špírková M., Jovanović S.: Studies of the thermal and mechanical properties of poly(urethanesiloxane)s cross-linked by hyperbranched polyesters. Industrial and Engineering Chemistry Research, 51, 10824-10832 (2012).

DOI: $10.1021 /$ ie300927z

[20] Džunuzović J. V., Pergal M. V., Poręba R., Vodnik V. V., Simonović B. R., Špírková M., Jovanović S.: Analysis of dynamic mechanical, thermal and surface properties of poly(urethane-ester-siloxane) networks based on hyperbranched polyester. Journal of Non-Crystalline Solids, 358, 3161-3169 (2012).

DOI: $10.1016 /$ j.jnoncrysol.2012.09.013

[21] Pergal M. V., Džunuzović J. V., Poręba R., Ostojić S., Radulović A., Špírková M.: Microstructure and properties of poly(urethane-siloxane)s based on hyperbranched polyester of the fourth pseudo generation. Progress in Organic Coatings, 76, 743-756 (2013). DOI: 10.1016/j.porgcoat.2013.01.007
[22] Vučković M. V., Antić V. V., Govedarica M. N., Djonlagić J.: Synthesis and characterization of copolymers based on poly(butylene terephthalate) and ethylene oxide-poly(dimethylsiloxane)-ethylene oxide. Journal of Applied Polymer Science, 115, 3205-3216 (2010). DOI: 10.1002/app.31416

[23] Malmström E., Johansson M., Hult A.: Hyperbranched aliphatic polyesters. Macromolecules, 28, 1698-1703 (1995).

DOI: $10.1021 / \mathrm{ma} 00109 \mathrm{a} 049$

[24] Vuković J.: Synthesis and characterization of aliphatic hyperbranched polyesters. $\mathrm{PhD}$ thesis, University of Osnabrück, Germany (2006).

[25] Pergal M. V., Antić V. V., Govedarica M. N., Goäevac D., Ostojić S., Djonlagić J.: Synthesis and characterization of novel urethane-siloxane copolymers with a high content of PCL-PDMS-PCL segments. Journal of Applied Polymer Science, 122, 2715-2730 (2011). DOI: 10.1002/app.33926

[26] Pergal M. V., Antić V. V., Tovilović G., Nestorov J., Vasiljević-Radović D., Djonlagić J.: In vitro biocompatibility evaluation of novel urethane-siloxane copolymers based on poly( $\varepsilon$-caprolactone)-block-poly (dimethylsiloxane)-block-poly(e-caprolactone). Journal of Biomaterials Science: Polymer Edition, 23, 1629-1657 (2012). DOI: $10.1163 / 092050611 X 589338$

[27] Pergal M. V., Antić V. V., Ostojić S., Marinović-Cincović M., Djonlagić J.: Influence of the content of hard segments on the properties of novel urethane-siloxane copolymers based on a poly( $\varepsilon$-caprolactone)-b-poly (dimethylsiloxane)-b-poly( $\varepsilon$-caprolactone) triblock copolymer. Journal of the Serbian Chemical Society, 76, 1703-1723 (2011). DOI: $10.2298 / \mathrm{JSC} 110307146 \mathrm{P}$

[28] Marand Å., Dahlin J., Karlsson D., Skarping G., Dalene M.: Determination of technical grade isocyanates used in the production of polyurethane plastics. Journal of Environmental Monitoring, 6, 606-614 (2004). DOI: 10.1039/B402775B

[29] Gindl M., Sinn G., Gindl W., Reiterer A., Tschegg S.: A comparison of different methods to calculate the surface free energy of wood using contact angle measurements. Colloids and Surfaces A: Physicochemical and Engineering Aspects, 181, 279-287 (2001). DOI: $10.1016 / \mathrm{S} 0927-7757(00) 00795-0$

[30] van Oss C. J., Good R. J., Chaudhury M. K.: Additive and nonadditive surface tension components and the interpretation of contact angles. Langmuir, 4, 884-891 (1988). DOI: $10.1021 / 1 \mathrm{a} 00082 \mathrm{a} 018$

[31] Hwang H-D., Kim H-J.: Enhanced thermal and surface properties of waterborne UV-curable polycarbonatebased polyurethane (meth)acrylate dispersion by incorporation of polydimethylsiloxane. Reactive and Functional Polymers, 71, 655-665 (2011). DOI: $10.1016 /$ j.reactfunctpolym.2011.03.004 
[32] Vince J., Orel B., Vilčnik A., Fir M., Vuk A. Š., Jovanovski V., Simončić B.: Structural and water-repellent properties of a urea/poly(dimethylsiloxane) solgel hybrid and its bonding to cotton fabric. Langmuir, 22, 6489-6497 (2006).

DOI: $10.1021 / 1 \mathrm{la060694a}$

[33] Bulacovschi V., Stanciu A., Rusu I., Căilean A., Ungureanu F.: Thermal stability and the behaviour in organic solvents of some poly(ester-siloxane)urethanes. Polymer Degradation and Stability, 60, 487-491 (1998). DOI: 10.1016/S0141-3910(97)00112-2

[34] Majumdar P., Stafslien S., Daniels J., Webster D. C.: High throughput combinatorial characterization of thermosetting siloxane-urethane coatings having spontaneously formed microtopographical surfaces. Journal of Coatings Technology and Research, 4, 131-138 (2007).

DOI: $10.1007 / \mathrm{s} 11998-007-9015-2$

[35] Jalbert C., Koberstein J. T., Yilgor I., Gallagher P., Krukonis V.: Molecular weight dependence and endgroup effects on the surface tension of poly(dimethylsiloxane). Macromolecules, 26, 3069-3074 (1993).

DOI: $10.1021 / \mathrm{ma} 00064 \mathrm{a} 012$

[36] Wang H. H., Mou J., Ni Y. H., Fei G. Q., Si C. L., Zou J.: Phase behavior, interaction and properties of acetic acid lignin-containing polyurethane films coupled with aminopropyltriethoxy silane. Express Polymer Letters, 7, 443-455 (2013).

DOI: 10.3144/expresspolymlett.2013.41
[37] Jiang H., Zheng Z., Song W., Li Z., Wang X.: Alkoxysilane functionalized polyurethane/polysiloxane copolymers: Synthesis and the effect of end-capping agent. Polymer Bulletin, 59, 53-63 (2007). DOI: $10.1007 / \mathrm{s} 00289-007-0748-y$

[38] Madhavan K., Reddy B. S. R.: Poly(dimethylsiloxaneurethane) membranes: Effect of hard segment in urethane on gas transport properties. Journal of Membrane Science, 283, 357-365 (2006).

DOI: $10.1016 /$ j.memsci.2006.07.005

[39] Mahoney C. M., Gardella Jr J. A., Rosenfeld J. C.: Surface characterization and adhesive properties of poly(imidesiloxane) copolymers containing multiple siloxane segment lengths. Macromolecules, 35, 52565266 (2002). DOI: $10.1021 / \mathrm{ma} 010353 \mathrm{y}$

[40] Chiou B-S., Schoen P. E.: Effects of crosslinking on thermal and mechanical properties of polyurethanes. Journal of Applied Polymer Science, 83, 212-223 (2002).

DOI: $10.1002 / a p p .10056$

[41] Pusztai E., Kenyó Cs., Nagy J., Wagner Ö.: The effect of some disiloxane chain extenders on the thermal and mechanical properties of cross-linked poly(siloxaneurethane)s. Express Polymer Letters, 7, 456-470 (2013). DOI: 10.3144/expresspolymlett.2013.42

[42] Alexandru M., Cazacu M., Cristea M., Nistor A., Grigoras C., Simionescu B. C.: Poly(siloxane-urethane) crosslinked structures obtained by sol-gel technique. Journal of Polymer Science Part A: Polymer Chemistry, 49, 1708-1718 (2011).

DOI: $10.1002 /$ pola. 24602 